\title{
Setting the stage for play for children with autism
}

\section{Opinion}

Many of the best ideas for research begin with planned or unplanned observations. As a psychologist, ABA therapist, and supervisor of educational and behavioral programs for children with autism, I observed children at play in the classroom, on the playground, and in recreational settings such as a swimming pool. Indoors, the children often didn't play at all. Instead of cooperatively building with tinker toys or blocks the child with autism would wave the sticks in front of his/her face in self-stimulation, or threw pieces around the room. On the playground, a child with autism might be fortunate to get a ride in a bicycle "side car" from an empathetic, neurotypical peer. Or maybe pushed on a swing. Fun for both! And children with autism often appeared indistinguishable from their peers in a swimming pool. The children enjoyed splashing, throwing or batting around a beach ball, yelling out at one another in fun.

I put these observations to the test in a research design alternating 5 minute play periods with fine-motor materials (tinker toys, blocks) with 5 minute periods of play with active gross-motor play equipment. These included a see-saw, boxes tied together to make a "train," rubberized equipment to jump/bounce on. The children here, unfamiliar with each other, were 4-9 years of age, one child with high functioning autism, one neurotypical peer. The results confirmed my informal observations: the pairs of children, videotaped behind a one way mirror did not play together in the fine-motor condition. Attempts to initiate play by the neurotypical peer were most often ignored by the child with autism, who preferred self-stim or sat unengaged. This reversed when the children were introduced into a gross-motor setting with one piece of equipment and also videotaped behind a one way mirror. The equipment itself helped to structure the interaction: e.g., each child taking a seat on the see-saw, or crawling through the boxes. What was most exciting for us was that the dramatic increases in play here generalized back into the following fine-motor setting. The children "figured out" how to interact together, the neurotypical child often providing clear direction. For example, "hockey sticks" were fashioned out of tinker toys, and the children hit a round piece, i.e., the puck, back and forth on the floor.

As follow up we asked naïve ("blind" to the purpose of the study, unfamiliar with the children) school teachers and peers to rate videotaped segments of the children on play together, use of language, desirability to have each child in his/her class. Their ratings from the

\author{
Volume II Issue 2 - 202I
}

Dean Alexander Ph. D
Therapist, USA

Correspondence: Dean Alexander Ph. D, Therapist, USA, Email deanalexanderphd@gmail.com

Received: June 14,2021 | Published: August 04, 202 I

three play conditions (baseline fine-motor, gross-motor, generalized fine-motor) tracked the data we gathered on a social interaction score sheet. The child with autism was viewed as better on all indicators during and after play in the gross-motor settings. The benefits of gross-motor play were "socially validated." Later we evaluated triads of children: two neurotypical peers and one high functioning autistic child. The play results were much the same for two thirds of these groups, even though the two neurotypical children could now have easily excluded the child with autism from interaction. The most successful forms of interaction included giving commands/feedback/ compliance; producing interjections (Wow! Yeah!) or statements of ongoing activity (Now we're jumping!).

It has been my great pleasure to witness successful interaction/ integration issuing from simple gross-motor settings. A youngster with autism led his basketball team to a nationally televised victory by coming off the bench and sinking several three point shots. (Learning to shoot "foul shots" is a great entry point for an even more simplified gross-motor activity that can be applauded by others.) There has been sports coverage of young men with autism successfully competing in track and field, and even amateur wrestling. Swimming, bowling, ping pong, sand bag toss or horseshoes, pool (on a table) are all wide open. The activities mentioned earlier are options to set the stage for younger children. Simple gross-motor activities can be natural "ice breakers" for our children without reliance on us nonpeers (i.e., teachers/parents) to do "the heavy lifting". 